\title{
The development of a multidimensional Consumer Perceived Value scale in ophthalmology services
}

\author{
Gheorghe Consuela-Mădălina, Purcărea Victor Lorin, Gheorghe Iuliana Raluca \\ "Carol Davila" University of Medicine and Pharmacy, Department of Marketing and \\ Medical Technology, Bucharest, Romania
}

Correspondence to: Iuliana Raluca Gheorghe, $\mathrm{PhD}$, Senior Lecturer, Department of Marketing and Medical Technology, "Carol Davila" University of Medicine and Pharmacy, 8 Eroii Sanitari Blvd., Code 050474, District 5, Bucharest, Romania,

E-mail: raluca.gheorghe@umfcd.ro

Accepted: October 17th, 2019

\begin{abstract}
Objective: The aim of this study was to investigate the dimensionality of Consumer Perceived value in Romanian ophthalmology services.

Material and Methods: The sample consisted of 173 consumers of private ophthalmology services, recruited using a systematic method. The design of the study was cross-sectional and the research instrument was a self-administered questionnaire, namely a Consumer Perceived Value Scale, developed by Chahal and Kumari. The dimensions of the Consumer Perceived Value were assessed by conducting an Exploratory Factor Analysis and the scale's reliability was checked with the Cronbach's alpha coefficient.

Results: The findings of the Exploratory Factor Analysis revealed that all initial factors loaded properly and the Cronbach's alpha coefficients had values greater than the recommended threshold of 0.70 . As such, the Consumer Perceived Value scale had a Cronbach's alpha coefficient of 0.77 and encompassed the following dimensions: transaction value, aesthetic value, efficiency value, self-gratification value, acquisition value and social interaction value.

Conclusions: Applying efficient value strategies in ophthalmology services may ensure consumer satisfaction, loyalty, positive word-of-mouth and offer competitive advantages. Keywords: Consumer Perceived Value, ophthalmology services, competitive advantage
\end{abstract}

\section{Introduction}

Nowadays, health care organizations are searching for a competitive advantage, as the health care service is not easily grasped by consumers, and at the same time, it is unwanted in comparison with other services [1]. Moreover, since consumers became value oriented, health care managers had to look for new methods to support them and grow their interest in the services provided so as a Marketing 3.0 era emerged [2]. The Marketing 3.0 era was linked to collaboration, globalization, and creativity, with the outcome of applying successful marketing practices [3]. After quality, consumer satisfaction and consumer loyalty, the consumer perceived value (CPV) has received the greatest attention in the strategic marketing.

The concept of value has been described as having an epistemic role in marketing, and may explain consumer behavior both before and after purchase [4]. In other words, value stands at the 
heart of every exchange relationship [5]. Still, Zeithaml defined perceived value as the consumer's overall assessment of the utility received in comparison to what is given [6], and according to Keller, consumers combine the perception of quality with the perception of cost in order to reach a balance in the shape of perceived value [7]. Despite the fact that literature on value is as broad and as extensive as possible [8], the most encountered characteristic of perceived value is that it represents a trade-off between benefits and sacrifices of consumers when they make a purchase decision [9]. Moreover, even if value is well documented and researched by scholars in marketing literature, most of the studies were conducted in developed countries or were confined to the goods sector. In addition, consumers have different perceptions about value because of their differences in preferences and financial abilities. As such, the conceptualization of CPV remains unclear and extremely divergent in literature [10]. There are two main approaches related to the conceptualization of consumer perceived value in scientific literature: the first approach describes perceived value, as being related to benefits, be they economic, social, and relational, and the second approach is composed of the sacrifices, be they in terms of price, time, effort, risks, and opportunities [11].

Although the CPV concept may be applied in all services sectors, the literature which deals with health care CPV is quite scarce. Accordingly, $\mathrm{CPV}$ in health care services is the difference between benefits and sacrifices. In health care services, the benefits are generally the outcome of excellent quality, referring to the process, functional and technical quality, whereas, sacrifices may be embodied by monetary costs and non-monetary costs, such as time spent, mental and physical stress [12]. Further, Prahalad and Hamel strongly believe that in health care services, perceived value is in fact a co-creation value, suggesting an "obsessive focus on personalized interactions between the consumer and the organization", and, specifically, "communities of informed, networked, empowered and active consumers" may trigger challenging changes in value creation as perceived after a medical treatment program [13]. Further, Choi et al. [14] and Ekrem and Fazil [15] concluded that little attention has been given to the CPV scale development in health care services. Thus, in order to have an in-depth insight of the antecedents and consequences of consumer perceived value in health care services, its dimensions should be explored so as to build and maintain long-term relationships between health care organizations and consumers, as well as, determine high levels of consumer satisfaction, trust and positive behavioral intentions.

The aim of this study was to investigate the dimensionality of consumer perceived value in Romanian ophthalmology services.

\section{Background}

In the systematic review on CPV literature, Sanchez-Fernandez and Iniesta-Bonillo [16] identified two research directions related to the dimensionality of the concept. The first research direction, which is widely embraced by the marketing literature, presents the consumer value concept as a unidimensional construct [6]. Obviously, the unidimensional approach has proved to be too narrow or simplistic to what consumers might experience in terms of value, while the second research direction is based on a multidimensional perspective $[\mathbf{9 , 1 7}$. Up to this moment, despite the fact that the multidimensional perceived value construct is not that much explored in the literature [16], it is preferred over the unidimensional construct [4]. Moreover, the multidimensional approach focuses on an integrative dimensions' framework, as illustrated in table $\mathbf{1 .}$ 
Table 1. The multidimensional approaches of the perceived value

\begin{tabular}{|c|c|c|}
\hline Year & Dimensions & Reference \\
\hline \multirow[t]{2}{*}{1991} & $\begin{array}{ll}\text { - } & \text { Social value } \\
\text { - } & \text { Emotional value } \\
\text { - } & \text { Functional value } \\
\text { - } & \text { Epistemic value } \\
\text { - } & \text { Conditional value }\end{array}$ & Sheth et al. [18] \\
\hline & $\begin{array}{ll}\text { - } & \text { Cognitive value } \\
\text { - } \quad \text { Affective value }\end{array}$ & Ekrem, Fazil [15] \\
\hline 1997 & $\begin{array}{ll}\text { - } & \text { Cognitive value } \\
\text { - } & \text { Emotional (psychological value) }\end{array}$ & Grönroos [19] \\
\hline 1999 & $\begin{array}{ll}- & \text { Social value } \\
\text { - } & \text { Emotional value } \\
\text { - } & \text { Functional value (price/ value for money) } \\
\text { - } & \text { Functional value (performance/ quality) } \\
\text { - } & \text { Functional value (versatility) }\end{array}$ & Sweeney, Soutar, Johnson [20] \\
\hline 2001 & $\begin{array}{ll}\text { - } & \text { Functional dimension (economic and quality) } \\
\text { - } & \text { Social dimension } \\
\text { - } & \text { Emotional dimension }\end{array}$ & Sweeney and Soutar [17] \\
\hline 2006 & 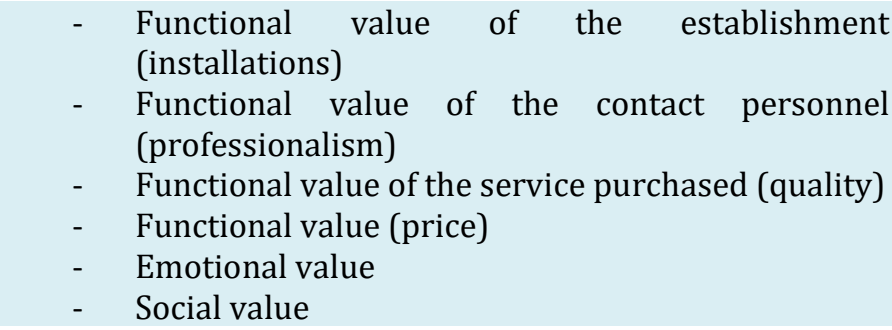 & Sanchez et al [21] \\
\hline
\end{tabular}

Source: Sanchez et al., p. 396 [21]

Based on a thorough literature review of $\mathrm{CPV}$ in health care services, the multidimensional approach comprising the following six constructs [12] (Fig. 1) was used in this study:

- transaction value consists of the psychological satisfaction gain from the service encounter, as for instance timely services delivered, personalized care, postmedical treatment, good medical advice, prompt response to consumers' requests;

- efficiency value comprises how effectively and efficiently the service provider delivers the health care services with the help of well-experienced staff, adequate visiting hours, explaining reason for medical problems, treatment;

- aesthetic value is the visual appeal of the health care organization and the ambient condition such as well-dressed employees, clean corridors and washrooms, clean clothing and bedding, proper ventilation;

- social interaction value is shaped by the impartial treatment such as nursing interaction, comfort zone with physician interaction, interaction with society;
- self-gratification value refers to the wellbeing of patients;

- acquisition value is defined by the overall net value concept.

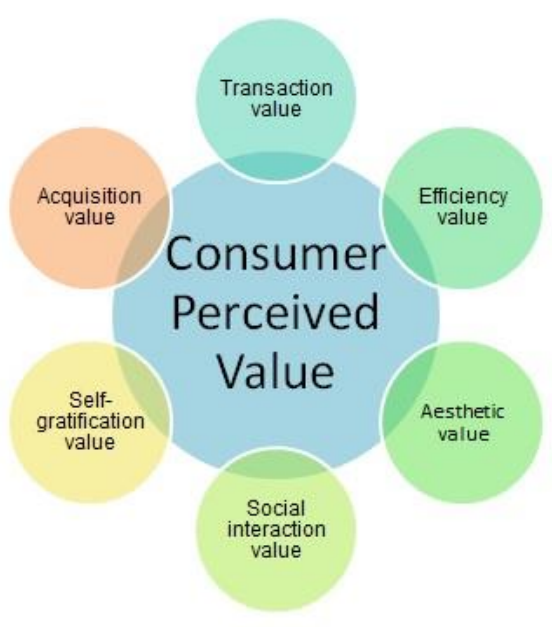

Fig. 1 Conceptual framework of the Consumer Perceived Value in Ophthalmology services

Accordingly, the hypothesis of the conceptual framework is that the Consumer Perceived Value in ophthalmology services is a 
multidimensional construct, made up of six dimensions.

\section{Material and Methods}

\section{- Participants}

Participants were the ophthalmology service consumers of a private health care organization, located in Bucharest, Romania. The inclusion criteria encompassed individuals who had an ophthalmology routine consultation, wore glasses for more than 3 years, had over 18 years and had no self-reported psychiatric morbidity, or other impairments which would cause difficulty in understanding certain concepts and words.

The selection of the participants was conducted on a systematic sampling method, suggesting that every third person scheduled for a routine ophthalmologic consultation was asked to take part in the study. Out of 200 initial respondents, 173 agreed to participate. Before filling in the questionnaires, all individuals completed written informed consent forms. As such, out of 173 respondents, the vast majority had the following characteristics: males (53.2\%), who graduated primary school $(27.2 \%)$ and were not married $(32.4 \%)$. The mean age of the sample was $42.09 \pm 7.12$.

\section{- Procedure}

The study design was cross-sectional and the data collection was performed between May 2019 and August 2019. The research instrument was a self-administered questionnaire which was printed and enclosed in sealable envelopes, so as to ensure confidentiality.

The questionnaire consisted of two sections:

- First section gathered socio-demographic information of the respondents such as age, gender, education level and marital status;

- The second section comprised the CPV scale, as developed by Chahal and Kumari [12] and referred to the 6 dimensions of CPV, namely, efficiency value, aesthetic value, self-gratification value, social interaction value, transaction value and acquisition value.

All items were measured with 5-point Likert scales, ranging from 1-Strongly Disagree to 5-Strongly Agree.

\section{- Data collection}

The data collection was assessed following a two stage approach for the CPV measurement scale. The first stage consisted of a pilot study conducted on 20 consumers after an ophthalmology routine consultation. Consequently, the items in the questionnaire were checked in order to provide appropriate responses, uncover ambiguous wording or errors. The outcome of the first stage revealed there were no items to be removed from the CPV scale.

The second stage of the research consisted of the self-administration of the 29 item questionnaire, as depicted in Table 2.

Table 2. The CPV measurement scale

\begin{tabular}{lll} 
Dimension & No. of items & Observations \\
Acquisition value & 4 & - \\
\hline Transaction value & 7 & 2 items are reversed \\
Efficiency value & 5 & - \\
Aesthetic value & 6 & 1 item is reversed \\
Social interaction value & 3 & - \\
\hline Self-gratification value & 4 & -
\end{tabular}

Source: Chahal and Kumari [12]

- Statistical Analyses

The data was analyzed with SPSS version 20. More exactly, to determine the underlying dimensions of the perceived value construct, an exploratory factor analysis (EFA) with Varimax rotation was conducted. A factor loading of more than 0.40 was treated as being appropriate to be included in the latent factor category. The adequacy of the factor analysis was established by the Kaiser-Meyer-Olkin measure of sampling adequacy and Bartlett's test of sphericity $(\mathrm{p}<0.001)$.

The reliability test, measured with Cronbach's alpha coefficient, was used to 
determine how strong the items of the questionnaire relate to each other. The internal consistency of the scale was deemed to be acceptable if it exceeded the threshold of 0.70 [22].

The threshold for statistical significance in all tests was $p<0.05$.

\section{Results}

The dimensionality of the Consumer Perceived Value in ophthalmology services was determined by the Exploratory Factor Analysis and the Cronbach's alpha coefficients of the 6 dimensions of the scale.

The findings of the Exploratory Factor Analysis are illustrated in Table 3. All items loaded properly on their initial factors and had values exceeded 0.7. So, the underlying dimensions of the CPV scale in the context of ophthalmology services are made up of the 6 dimensions. The Cronbach's alpha coefficients of all factors had values greater than 0.7 .

Table 3. The Exploratory Factor Analysis Results

\begin{tabular}{|c|c|c|c|c|}
\hline Factors & $\begin{array}{l}\text { Factor } \\
\text { Loading }\end{array}$ & Eigenvalue & $\begin{array}{l}\text { Explained } \\
\text { Variance }\end{array}$ & $\begin{array}{l}\text { Cronbach's alpha } \\
\text { coefficient }\end{array}$ \\
\hline Transaction value & & \multirow[t]{8}{*}{4.70} & \multirow[t]{8}{*}{16.22} & \multirow[t]{8}{*}{0.91} \\
\hline Transaction value_it1_rev & 0.838 & & & \\
\hline Transaction value_it2 & 0.825 & & & \\
\hline Transaction value_it3 & 0.788 & & & \\
\hline Transaction value_it4 & 0.797 & & & \\
\hline Transaction value_it5 & 0.786 & & & \\
\hline Transaction value_it6_rev & 0.802 & & & \\
\hline Transaction value_it7 & 0.851 & & & \\
\hline Aesthetic value & & \multirow[t]{7}{*}{4.20} & \multirow[t]{7}{*}{14.49} & \multirow[t]{7}{*}{0.91} \\
\hline Aesthetic value_it1 & 0.838 & & & \\
\hline Aesthetic value_it2 & 0.813 & & & \\
\hline Aesthetic value_it3 & 0.829 & & & \\
\hline Aesthetic value_it4 & 0.820 & & & \\
\hline Aesthetic value_it5 & 0.817 & & & \\
\hline Aesthetic value_it6_rev & 0.859 & & & \\
\hline Efficiency value & & \multirow[t]{6}{*}{3.53} & \multirow[t]{6}{*}{12.20} & \multirow[t]{6}{*}{0.89} \\
\hline Efficiency value_it1 & 0.827 & & & \\
\hline Efficiency value_it2 & 0.831 & & & \\
\hline Efficiency value_it3 & 0.846 & & & \\
\hline Efficiency value_it4 & 0.843 & & & \\
\hline Efficiency value_it5 & 0.814 & & & \\
\hline Self-gratification value & & \multirow[t]{5}{*}{3.04} & \multirow[t]{5}{*}{10.50} & \multirow[t]{5}{*}{0.88} \\
\hline $\begin{array}{l}\text { Self-gratification } \\
\text { value_it1 }\end{array}$ & 0.886 & & & \\
\hline $\begin{array}{l}\text { Self-gratification value } \\
\text { it2 }\end{array}$ & 0.841 & & & \\
\hline $\begin{array}{l}\text { Self-gratification value } \\
\text { _it3 }\end{array}$ & 0.847 & & & \\
\hline $\begin{array}{l}\text { Self-gratification value } \\
\text { it4 }\end{array}$ & 0.860 & & & \\
\hline Acquisition value & & \multirow[t]{5}{*}{2.81} & \multirow[t]{5}{*}{9.71} & \multirow[t]{5}{*}{0.85} \\
\hline Acquisition value_it1 & 0.826 & & & \\
\hline Acquisition value_it2 & 0.841 & & & \\
\hline Acquisition value_it3 & 0.835 & & & \\
\hline Acquisition value_it4 & 0.823 & & & \\
\hline Social interaction value & & \multirow[t]{2}{*}{2.28} & \multirow[t]{2}{*}{7.89} & \multirow[t]{2}{*}{0.83} \\
\hline Social interaction & 0.869 & & & \\
\hline
\end{tabular}




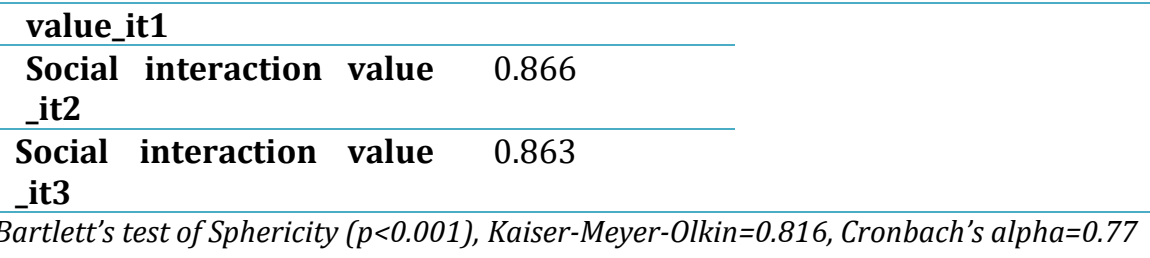

\section{Discussion}

The development of a multidimensional CPV scale in the context of ophthalmology services may have significant theoretical and practical implications. As such, this study extends the literature on consumer perceived value by offering an in-depth insight of its meaning and measurement. Specifically, our study tested a six-item dimensional CPV scale in ophthalmology services.

Findings revealed that the consumers' perceived value of ophthalmology services is based on the following dimensions: transaction value, efficiency value, aesthetic value, selfgratification value, acquisition value and social interaction value. In other words, ophthalmology services managers should focus on providing value to their consumers by elaborating efficient strategies based on the six value dimensions.

Applying efficient value strategies may ensure consumer satisfaction, loyalty, positive word-of-mouth, as well as, offer competitive advantages. Moreover, from a consumer's point of view, obtaining value is a fundamental purchase goal and it becomes a core element in the exchange process, which may be shaped by several benefits, such as cognitive benefits, reflected in knowledge acquisition, economic benefits, designating monetary compensation, hedonic benefits in enjoyment and excitement, personal benefits suggested by recognition, status and social esteem, practical benefits concerned with real life implications and, last, the social benefits, which are reflected in the established relationships with other consumers. From the organization's perspective, the most critical source of competitive advantage is the creation of consumer value, which would replace the quality management paradigm [9] and it would be the ground for all marketing activities [23].

According to Weinstein, the S-Q-I-P diamond framework depicts the antecedents of value, namely, service, image, price and quality
[2] (Fig. 2). The backbone components of an organization's offerings (quality and service) are represented on the vertical axis of the diamond model, whereas on the horizontal axis, the image and price provide cues for the target audiences. Creating value for consumers through the diamond model will provide a solid business philosophy for the organization, guide all strategic decisions, and trigger positive business performance.

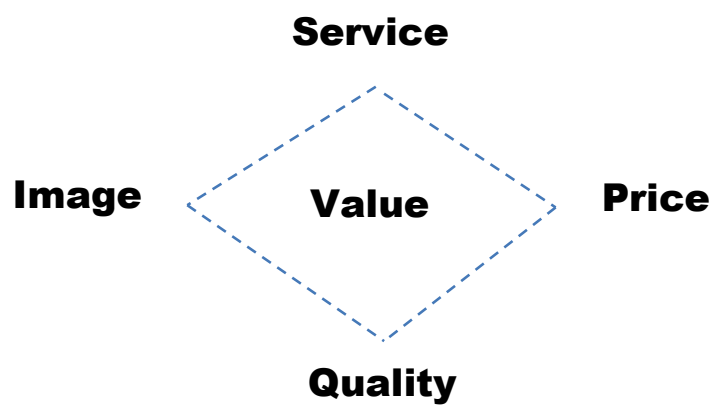

Source: Weistein, p. 51 [2] (All rights reserved)

Fig. 2. The S-Q-I-P diamond framework

Value oriented marketing strategies may bring the following advantages to an ophthalmology organization [2]:

- Understand consumers' choices and needs;

- Identify potential consumer segments;

- Increase the competitive options and diminish threats;

- Improve service quality;

- Concentrate on what is meaningful to consumers;

- Build consumer loyalty;

- Develop strong relationships with consumers.

The limitations of this study emphasize some future research directions. Thus, the focus on private health care services, with specific interest in ophthalmology services, leads to an 
extension suggestion, namely, to investigate CPV in public health care services as well. Moreover, we encourage the comparison between the private and public health care services in terms of CPV. The generalizability of our findings should be done with caution, as the study sample comprised consumers from Bucharest and we strongly recommend the CPV scale to be validated in other contexts and health care specialties, in order to determine which dimension of perceived value, becomes the most important. In addition, several causal relationships should be empirically assessed, meaning to explore the established relationships between CPV and several other variables, such as service quality, internal marketing strategies, consumer loyalty, consumer satisfaction, external marketing strategies, word-of-mouth, organizational behavior in the context of ophthalmology services.

\section{Conclusions}

The development of a multidimensional CPV scale in the context of ophthalmology services proved to have practical implications in the shape of meaning and measurement. The CPV scale in ophthalmology services was made up of the following dimensions: transaction value, efficiency value, aesthetic value, selfgratification value, acquisition value and social interaction value.

Elaborating and implementing efficient value strategies in ophthalmology services may increase consumer satisfaction, loyalty, positive word-of-mouth and offer competitive advantages.

\section{References}

1. Berry LL, Bendapudi N. Health Care A fertile field for service research. Journal of Service Research. 2007; 10(2),111-122.

2. Weinstein A. Superior customer value. Finding and Keeping Customers in the Now Economy. 2019, Routledge, New York

3. Kotler P, Fox KFA. Strategic Marketing for Educational Institutions. 1995, Englewood Cliffs, New Jersey, Prentice-Hall.

4. Gallarza MG, Gil-Saura I, Holbrook MB. The value of value: Further excursions on the meaning and role of customer value. Journal of Consumer Behavior. 2011; 10(4),179-191.
5. Ballantyne D, Christopher M, Payne A. Relationship marketing: Looking back, looking forward. Marketing Theory. 2003; 3(1),159-166.

6. Zeithaml VA. Consumer perceptions of price, quality and value: A means-end model and synthesis of evidence. Journal of Marketing. 1988; 52(3),2-22.

7. Keller K. Strategic brand management: building, measuring, and managing brand equity. 1998, Upper Saddle River, New Jersey: Prentice Hall.

8. Woodall T. Conceptualising "Value for the customer": An attributional, structural and dispositional analysis. Academy of Marketing Science Review. 2003; 12:1-31.

9. Woodruff RB. Customer value: The next source of competitive advantage. Journal of Academy of Marketing Science. 1997; 25,139-153.

10. Gounaris SP, Tzempelikos NA, Chatzipanagiotou K. The relationships of customer-perceived value, satisfaction, loyalty and behavioural intentions. Journal of Relationship Marketing. 2007; 6(1),63-87.

11. Grewal D, Monroe K, Krishnan R. The effects of pricecomparison advertising on buyers' perceptions of acquisition value, transaction value and behavioural intentions. Journal of Marketing. 1998; 62,46-59.

12. Chahal H, Kumari N. Consumer Perceived Value: The development of a Multiple Item Scale in Hospitals in the Indian Context. International Journal of Pharmaceutical and Healthcare Marketing. 2012. doi: 10.1108/17506121211243086.

13. Prahalad CK, Hamel G. Competing for the future, 1994, Harvard Business School Press.

14. Choi K-S, Cho W-H, Lee S, Lee H, Kim C. The relationship among quality, value, satisfaction and behavioural intention in health care provider choice: a South Korean Study. Journal of Business Research. 2004; 57,913-921.

15. Ekrem C, Fazil K. Customer Perceived Value: the development of a multiple item scale in hospitals. Problems and Perspectives in Management. 2007; 5(3),252-268.

16. Sanchez-Fernandez R, Iniesta-Bonillo MA. The concept of Perceived Value: A systematic review of the research. Marketing Theory. 2007; 7(4),427-451.

17. Sweeney JC, Soutar G. Consumer perceived value: the development of multiple item scale. Journal of Retailing. 2001; 77(2),203-220.

18. Sheth JN, Newman BI, Gross BL. Why we buy what we buy: a theory of consumption values. Journal of Business Research. 1991; 22(2),159-170.

19. Gronroos Ch. Value-driven relational marketing: from products to resources and competencies. Journal of Marketing Management. 1997; 13(5),407-420.

20. Sweeney J, Soutar G, Johnson LW. The role of perceived risk in the quality-value relationship: a study in a retail environment. Journal of Retailing. 1999; 75(1),77-105.

21. Sanchez J, Callarisa LLJ, Rodriguez RM, Moliner MA. Perceived value of the purchase of a tourism product. Tourism Management. 2006. 27(4).

22. Nunnally, JC. Psychometric theory, 1978, New York, McGraw-Hill.

23. Holbrook MB. Consumer Value. A framework for analysis and research. 1999, Sage, London: Routledge. 